- A visiting 'rapid response' CNS

- A nurse led triage clinic

- Increased triage nurse hours

The CNS team have used audit to truly 'hear' what is happening in practice and as a result have used this knowledge to lead service redesign- a key aspect of the CNS role identified by National Cancer Action Team (2010)

\section{P15 THE RIGHT WAY TO WRITE? DEVELOPMENT OF NEW DOCUMENTATION FOR COMMUNITY PALLIATIVE CARE}

Hilary McPolin, Mary McMullan, Grainne McGinnity, Fiona Flynn. Northern Ireland Hospice, Belfast, N. Ireland

\subsection{6/bmjspcare-2013-000591.37}

Background/Context Efficient, comprehensive documentation not only provides a record of care, but also reflects the quality of that care whilst reinforcing care standards. However, documentation in palliative care has often fallen short of these ideals (McEvoy, 2000). Following the development of a centralised triage system for new referrals to a community palliative care service, it was recognised that there was duplication of information being recorded by both the triage staff and the community nurses. There was also a general consensus that the triage documentation should be incorporated into the nursing assessment tool to reflect the patients' journey and promote continuity of care.

Aim To develop user friendly, time efficient documentation that provides a comprehensive holistic assessment of specialist palliative care patients and their families.

Approach Used A project team was formed with representatives from the triage team and the community nursing teams. Following a review of in-house documentation, Liverpool Care Pathway (LCP) and assessment tools from both hospital and community palliative care teams, a new tool was developed and piloted. Minor changes were made, based on the initial evaluations and subsequently, a second pilot was undertaken before the tool was finalised.

Outcomes The new tool was rolled out to all the community teams in January 2013. Feedback to date suggests a reduction in both the amount of duplication as well as the amount of time spent on recording the required information.

Application to Hospice Practice The new documentation tool reflects a holistic, comprehensive, specialist palliative care nursing assessment, in a user friendly, time efficient format. It has improved communication and accessibility of information and recognises the need to increase the capacity for recording the needs of carers. Better documentation can lead to better patient care.

\section{P16 PLANNING YOUR WEEK: A NEW MODEL FOR RURAL WORKING}

Derek Hart, Cathy Martin, Maggie Draper. St Luke's Hospice Plymouth, Plymouth, United Kingdom

\subsection{6/bmjspcare-2013-000591.38}

An examination of caseload management is currently being undertaken by 2 community palliative care nurses who cover a large area, encompassing the environs of city to remote moor land. The remote areas have no mobile telephone access and poor infrastructure.
The caseload was analysed and divided into 7 geographical areas (zones). Visits were to be arranged to these zones on specific days to optimise efficiency, taking into account $\mathrm{mdt}$ commitments.

The aims were:

- To increase efficacy of visits, reduction of interruptions

- Reduce travelling time and mileage

- Improve response time from referral to first visit,

- Improve reliability and therefore develop stronger integrated working.

- Improve wellbeing and support of the CNS.

- Move from reactive "fire fighting" to proactive care where crises were predicted where possible.

The approach used was:

- A time table of areas and days was created.

- Two nurses covered the caseload of approx 60 patients.

- The timetable took into account mentorship needs of the new CNS. It promoted men- tee and mentor working in neighbouring zones. Meeting places in the field (literally!) were highlighted should support be required.

- 1 nurse per day was allocated to triage calls and trouble shoot.

- The administrative team were involved in planning and were aware of who to call.

Outcomes - to be measured / reviewed September 2013

- Supportive mentorship of new CNS in rural environment

- Reduced Mileage

- Reduced interruption from mobile phone calls.

- Reduced sickness

- Improved record keeping. The two nurses were reliant on each others records to provide continuity of care.

- A more efficient use of laptops reducing the need to return to base.

- Development of professional relationship between nurses encouraging peer review.

- Improved relationships with GPs and community nursing teams

\section{P17 THE COMMUNITY AND HOSPICE HOME NURSING SERVICE}

${ }^{1}$ Lesley Spencer, ${ }^{2}$ Karen Masetti, ${ }^{3}$ Gina Starnes. ${ }^{1}$ Princess Alice Hospice, Esher, England, ${ }^{2}$ Central Surrey Health, Ewell, England, ${ }^{3}$ St Catherine's Hospice, Crawley, England

10.1136/bmjspcare-2013-000591.39

Background/ Context End of Life care support throughout Surrey had been fragmented and lacked an integrated approach. As a result three organisations came together to form the 'Community and Hospice Home Nursing Service'.

The service supports a multi-disciplinary partnership approach to delivering nursing care at home. Central Surrey Health (CSH), and two Independent Hospices; Princess Alice Hospice (PAH) and St Catherine's Hospice ( $\mathrm{StCH}$ ) are now delivering a seamless seven day, 24 hour service.

Main Aim To provide care that avoids inappropriate hospital admissions and enables more people to be cared for and die in their place of choice. 
Approach Used The service was designed following patient and carer feedback and necessitated hospices working together across traditional boundaries.

Key elements

- Co-ordination via a single point of access

- Additional clinical provision of night and day care by Staff Nurses and Senior Health Care Assistants.

- Partnership approach to care delivery.

Importantly the Hospices involved are extending their reach to support those who have not or may not need referral to specialist palliative care.

Outcomes Ninety eight percent of patients achieved their preferred place of care with $95 \%$ achieving their preferred place of death; $85 \%$ of those who were referred to avoid an admission to hospital achieved this; $28 \%$ of patients had a non- malignant diagnosis. The key performance indicator, aimed at increasing the number of referrals on $\mathrm{CSH}$ end of life care register by $5 \%$ was achieved with a $70.4 \%$ increase.

Application to hospice practice Commissioners were delighted with the multi-professional and integrated partnership approach to care delivery and the solution focussed proactivity. They champion the partnership as a model for the future. The community and Hospice home nursing service suggests that an integrated approach to care delivery can improve outcomes whilst being cost effective.

\section{P18 "THIS IS SO BIG"}

Sue Shrimpton. Princess Alice Hospice, Esher, UK

\subsection{6/bmjspcare-2013-000591.40}

Background The death of a parent in childhood is one of the most profound losses a child will ever experience. Supporting children whose parents are terminally ill is therefore an emotive topic. Much research states that if the needs of the child are not met, there can be immediate and long terms problems such as delinquency.

A major driver for this study came from children talking at a child bereavement group telling me they had overheard conversations about their parent' condition, but because they had not been told directly they felt they could not voice their worries.

Aim To explore community palliative care clinical nurse specialists (CPCCNS) experience of supporting families with children.

Methods Using a phenomenological approach, a purposeful sample of eight CPCCNS' were interviewed. Interviews were recorded and transcribed verbatim. Using Colazzi's analysis, themes were identified.

Results The themes were:

- Doubted ability

- Not their role

- Greater time in role increased confidence in ability

- Acknowledgement of importance of support

- Age, culture and religious differences

- Referrals to other healthcare professionals and charities

- Parallels in CPCCNS own life seemed to aid empathy

Conclusion Care of the 'whole' family is central to the WHO (2011) definition of palliative care. CPCCNS' are in a prime position to support children at their most vulnerable, otherwise a delay may mean the child remains unsupported and there is a greater risk of issues during parents illness and following bereavement. This study highlights the role of the CPCCNS' using data and narrative from interviews.

Implications for hospice practice Adequate support and training is essential in providing CPCCNS' with the tools to support children of dying parents so they can feel able and more confident in this area of support.

\section{P19 WIDENING ACCESS TO HOSPICE SERVICES: THE DEVELOPMENT OF A 7/7 COMMUNITY SPECIALIST PALLIATIVE CARE NURSE SERVICE AND A RAPID RESPONSE SERVICE PILOT}

Deborah Saunby. St Lukes Hospice, Sheffield, England

10.1136/bmjspcare-2013-000591.41

Background and Context In response to national Peer Review Standards and NICE Guidance to offer 7 day face to face visiting an opportunity to pilot a service within a hospice based Community Specialist Palliative Care Nursing Team arose. Within this the development in order to be more responsive a Rapid Response service has been developed.

Aim To widen access for patients with specialist palliative care needs to holistic assessment by a Clinical Nurse Specialist and offer greater flexibility in options for home assessments. To offer an urgent response based on clinical need 7 days a week, for crisis intervention. To assess need for urgent admission to an inpatient unit bed or facilitate the patient remaining in their own home if desired.

Approach Used A review of caseload configuration across the city with the development of 4 zone teams. A significant investment in resources to support an additional 3 WTE Band 6 Associate Community Specialist Palliative Care Nurses was agreed for a temporary period of 6 months, with successful recruitment to the posts.

All referrals to the hospice service are reviewed through a multi professional meeting and triaged according to urgency and priority, with the capacity for immediate home assessment, 7 days a week and greater flexibility for managing routine and follow up reviews.

Outcomes Measures will be determined through review and analysis of all Rapid Response visits to determine whether patient preference over place of care has been met.

External stakeholders opinion regarding perceived satisfaction with $7 / 7$ access and rapid response in the management of community patients.

Cost- benefit analysis of investment of resources on improved caseload management to inform strategic service development.

\section{P20 THE SIKH POPULATION OF NORTH WEST KENT: EXPLORING THE LIVED EXPERIENCE OF CARING FOR A DYING RELATIVE AT HOME}

Margaret Mary Cowan, Bridget Withell. EllenorLions Hospices, Gravesend, England

10.1136/bmjspcare-2013-000591.42

Research Aims To explore the Sikh population's experience of caring for a dying relative at home and develop an understanding of their experiences.

Background /literature review Hill \& Penso, (1995) reported under-use of specialist palliative care services by minority ethnic groups with minimal improvement noted in present day (Gunaratnam, 2007, DoH, 2008). Often, end-of-life needs are unfulfilled ( Worth et al, 2009, DoH, 2010, DoH, 2011). Locally, 